\title{
Living arrangements and nutritional status of under-five children in
}

\section{Sub-Saharan Africa}

\section{Pamela Chirwa Banda ${ }^{1}$, Lorretta Favour C. Ntoimo ${ }^{2}$ \& Emmanuel O. Olamijuwon ${ }^{3}$}

\author{
${ }^{1}$ Ministry of Education, Provincial Education Office, Lusaka, \\ Zambia. \\ 2 Department of Demography and Social Statistics, Federal University, \\ Oye-Ekiti, Ekiti State, Nigeria \\ ${ }^{3}$ Demography and Population Studies Programme, Schools of Public Health and Social Sciences, \\ University of the Witwatersrand, Johannesburg, South Africa \\ pcbnamwinga@yahoo.com
}

\begin{abstract}
Despite efforts aimed at improving the nutritional status of children under-five years, only a slow progress has been made in Sub-Saharan Africa (SSA). Using data from the latest Demographic and Health Surveys of 17 countries in SSA, we illuminate the association between living arrangement and the nutritional status of 144,765 children under five years. Results showed that living with only the father compared to both parents was associated with a higher risk of malnutrition in SSA [OR:I.I8, $\mathrm{Cl}$ :I.03-I.30] while not living with both parents was associated with a higher risk of malnutrition in West Africa [OR:I.25, Cl:I.02-I.54]. Lower risk of malnutrition was observed among children residing in households headed by their mother compared to those headed by their father in West Africa [OR:0.76, Cl:0.66-0.87] and SSA [OR:0.83, Cl:0.77-0.90]. These results suggest that with whom and where children live as well as biological relationships are vital in improving children's nutritional status in SSA.
\end{abstract}

Keywords: living arrangements, nutritional status, malnutrition, sub-Saharan Africa, under-fives

\section{Introduction}

Globally, an estimated $26 \%$ of all under-five children are stunted, $8 \%$ are wasted, and about $16 \%$ are underweight (UNICEF, WHO \& WORLD BANK, 20I2). In sub-Saharan Africa (SSA), about $41 \%$ of under-five children are malnourished (Briend \& Collins, 2010). Sub-Saharan Africa also has the second highest prevalence of underweight among children under five years and about one-third of wasted children in the world are in SSA (UNICEF, 20I4). The high prevalence of malnutrition in the region has been attributed in part to poverty, ignorance, large family size, poor policy implementation, corruption, and HIV/AIDS (Wachs, 2008; Karaolis, et al., 2007). Poor environmental conditions, political instability and slow economic growth are also perceived to be contributing factors (Bain, et al., 20l4).

Estimated to contribute to more than one-third of all child deaths and about $3 \%$ of disability-adjusted life years (DALYs), poor nutrition has detrimental effects on child health and development but is rarely listed as a direct cause (Briend \& Collins, 2010; deOnis, et al., 2004; Black, et al., 2003). In hospitals in developing countries, severely malnourished children comprise a sizeable proportion of paediatric deaths (Karaolis, et al., 2007; deOnis, et al., 2004). Among survivors, the risk of morbidity is often higher among children with poor nutritional status because of the susceptible nature of young children to infections resulting from contaminated foods and liquids which are more common in developing countries (Ehrhardt, et al., 2006).

The detrimental effect of malnutrition is however not limited to child health and survival but also linked with many social and economic deprivations which impede and hamper economic and social development (Mahmood, et al., 20I4; Neumann, et al., 2004; Berkman, et al., 2002). In the short term, its effect ranges from compromised growth and a changed body composition to changed brain development and altered metabolic, hormones, receptor and gene functions (Kar, Rao \& Chandramouli, 2008; Levitt, et al., 2006; Rajagopolan, 2003). In the long term, its effects range from compromised immunity to reduced cognitive 
development, decreased educational performance, NCDs, including ischaemic heart disease and stroke (Venables \& Raine, 2016; Wachs, 2008; Berkman, et al., 2002; Grantham-McGregor, Fernald, \& Sethuraman, 1999; Barker, 1997).

Unless efforts are increased, the possibilities of achieving the sustainable development goals especially with regards to eliminating hunger, reducing under-five deaths, and promoting good health for persons at all ages by $2030 / 35$ is very low. Given the potential health, the social and economic implications of malnutrition, renewed efforts are needed with regards to examining the nature, magnitude and determinants of under-five malnutrition (Asfaw, et al., 2015). Without these, malnourished children will develop into stunted, disadvantaged, 'incompetent' individuals who could perpetuate the malnutrition- poverty cycle.

Although several studies have examined aspects of children's nutritional status in SSA, majority of these studies have done so with less emphasis on living arrangement that is, where and with whom a child lives (Olamijuwon et al., 2017; Asfaw et al., 2015; Ayana, Hailemariam, \& Melke, 2015; Motbainor, Worku, \& Kumie, 2015; Egata, Berhane, \& Worku, 2014; Ntoimo \& Odimegwu, 20l4; Adekanmbi, Kayode, \& Uthman, 2013; Gurmu, \& Etana, 2013). For instance, Ntoimo \& Odimegwu (2014) found that children of single mothers were more likely to be stunted compared to children of mothers who were married (Ntoimo \& Odimegwu, 20l4). Similarly, a study of household structures and its implications for child malnutrition in Ethiopia found that children in single parent nuclear households were more vulnerable to malnutrition than those in two-parent nuclear and extended households (Gurmu, \& Etana, 2013).

Given the potential health, the social and economic implications of malnutrition, renewed efforts are needed with regards to its magnitude and determinants, both of which may enhance public health measures to speed up the prevention of deaths or complications caused by malnutrition (Asfaw, et al., 2015). Without these, malnourished children will develop into stunted, disadvantaged, 'incompetent' individuals who could perpetuate the malnutrition- poverty cycle. The changes taking place in living arrangements in sub-Saharan Africa occasioned by economic downturns also necessitates the need to investigate the role of living arrangement that is, where and with whom a child lives especially taking into consideration single fathers and not only mothers.

As a result, we examine the relationship between children's living arrangement and the risk of malnutrition. Our major argument is that the lower work capacity and an increased risk of many children's living arrangements are critical in improving our understanding of the causes of malnutrition especially since it reflects, biological relationships and family type. We adapted the UNICEF (1990) framework for studying the relations between living arrangements, poverty, food insecurity, and other underlying and immediate causes of child nutritional status. According to the model, nutritional status is the outcome of the interplay among basic, underlying and immediate factors. The basic factors consist of structural characteristics - urban-rural residence and background (remote)-and household characteristics-living arrangements, wealth index, sources of drinking water and toilet facilities-as well as maternal characteristics-education, marital status and age. These factors indirectly influence the underlying factors of child-related variables and directly influence the immediate factors that affects children's nutritional status. We used the terms nutritional status and nutritional health interchangeably throughout this paper.

\section{Data and methods}

We used the household member recode data from the most recent demographic and health surveys of 17-sub-Saharan African countries collected between 2013 and 2016. These data were subsequently extracted, pooled and divided into regions according to the classification of the African Union. Data for Central Africa was pooled from Chad 20/4-I5, and Congo DRC 2013-14. East Africa data was pooled from Kenya 20I4, Rwanda 20I4-I5, and Tanzania 2015-16. Data for West Africa was pooled from Gambia 2013, Ghana 2014, Liberia 2013, Mali 201213, Nigeria 20I3, Sierra Leone 20I3, and Togo 20I314. Southern Africa data from Lesotho 20I4, Malawi 2015-16, Namibia 2013, Zambia 2013-14 and Zimbabwe 2015. Children under 2years were measured lying down on the board (recumbent length) and standing height was measured for all other children.

Study Population and Sample: Population of interest in this study are under-five children between 6-59 months whose anthropometric data were collected and were usual residents of the selected households. The sample for this study was a weighted distribution of 126,217 under-five children in sub-Sahara Africa, 15\% of which were from the Central African region, 22\% from East Africa, 25\% from Southern Africa and about 38\% from the West Africa region. From Table I, most of the children in sub-Sahara Africa (7I\%) and in all the sub-regions are living with both parents. Very few under-five children in SSA (2\%) are residing with only their father and less than $10 \%$ in SSA and the sub-regions reside with 
none of their parents. The majority of the children while close to about one-quarters reside in a household not headed by child's father or mother.

Only about one-third of the children reside in richer or richest households of SSA (35\%) and sub-regions. Close to $90 \%$ of the children reside in a household headed by an adult who is between 15-64 years while children in child-headed households constitute about $6 \%$ of the sample. Most of the under-fives also reside in the rural place of residence and observed sex ratios seem to be similar with almost equal percentage in most of the regions. Children above 12 months (one year) constitute about $90 \%$ of the sample in SSA and sub-regions. About one-third of the children in SSA, Southern Africa and West Africa had a preceding birth interval between 18-35months. The mean number of under-five children in the households was highest in Central Africa (2.4) and lowest in the East (I.8) and Southern (1.9) African regions

\section{Variable description}

Outcome Variable in this study is under-five nutritional status which was dichotomized as nutritionally healthy (0), and malnourished (I). Under-fives that were not stunted, wasted, underweight nor overweight were categorised as being 'nutritionally healthy' while those that were wasted, stunted, overweight or underweight were described and classified as being "malnourished". Wasting among under-fives was described as weightfor-height Z-score less than -2 standard deviations reside in a household headed by the child's father ( $\mathrm{WHZ}<-2 \mathrm{SD})$ for all under-fives (6-59 months), stunting was described as height-for-age score less than -2 standard deviation (HAZ<-2 SD), underweight as weight-for-age score less than -2 standard deviation (WAZ $<-2$ SD) and overweight as weight-for-age score above 2 standard deviations and weight-for-height Z-score less than -2 standard deviations (WAZ>2 SD and WHZ > $2 \mathrm{SD}$ ).

Main predictor variable for this study is children's living arrangement to examine if the parents of an under-five are alive and residing in the same household with the child. This variable was generated from the combination of each child's father and mother's line-number as well as their survival status. The variable was categorized as 'living with both parent' (I) for under-fives reported to be living with both biological parents, 'living with only mother' (2) for under-fives living with only their mother because the father is dead or he doesn't reside in the household, 'living with only father' (3) for under-fives living with only their father because the mother is dead or she doesn't reside in the household and 'not living with any' for those who are not living with their biological parent because both or one of the parent(s) are/is dead or because both are alive but are not living in the same household with the child.

Control variables include household characteristics like gender and age of household head, household wealth, household size, and place of residence. We also included in the models, child characteristics like child sex and age, and interval

Table I: Socio-economic and demographic profile of under-fives in sub-Sahara Africa

Central Africa East Africa Southern Africa West Africa Sub-Sahara Africa

$\begin{array}{lccccc}\text { Living Arrangement } & & & & & \\ \text { Living with Both Parents } & 73.3 & 62.6 & 67.9 & 75.7 & 70.6 \\ \text { Living Only with Mother } & 19.8 & 26.6 & 24.6 & 16.6 & 21.2 \\ \text { Living only with Father } & 2.0 & 1.1 & 1.2 & 2.0 & 1.6 \\ \text { Not Living with Any } & 4.9 & 9.7 & 6.4 & 5.6 & 6.6 \\ \text { Household Head } & & & & & \\ \text { Child's Father } & 72.1 & 57.7 & 64.0 & 72.0 & 67.0 \\ \text { Mother } & 11.4 & 15.1 & 14.6 & 8.5 & 11.9 \\ \text { Others } & 16.5 & 27.2 & 21.3 & 19.5 & 21.1 \\ \text { Household Wealth } & & & & & \\ \text { Poorest } & 21.8 & 24.1 & 24.8 & 22.1 & 23.2 \\ \text { Poorer } & 22.0 & 22.4 & 21.7 & 22.2 & 22.1 \\ \text { Middle } & 20.2 & 20.1 & 18.9 & 19.8 & 19.7 \\ \text { Richer } & 20.0 & 18.7 & 17.5 & 19.1 & 18.7 \\ \text { Richest } & 16.0 & 14.7 & 17.2 & 16.8 & 16.3\end{array}$


Age of Household Head

\begin{tabular}{|c|c|c|c|c|c|}
\hline Youth $(<24$ Years & 5.6 & 6.7 & 5.1 & 3.1 & 4.7 \\
\hline Working Age (I5-64) & 89.9 & 86.0 & 88.8 & 89.1 & 88.5 \\
\hline Aged (65 + Years) & 4.5 & 7.3 & 6.1 & 7.8 & 6.8 \\
\hline \multicolumn{6}{|l|}{ Place of Residence } \\
\hline Urban & 24.0 & 27.7 & 28.6 & 35.6 & 30.4 \\
\hline Rural & 76.0 & 72.3 & 71.4 & 64.4 & 69.6 \\
\hline \multicolumn{6}{|l|}{ Child Sex } \\
\hline Male & 50.0 & 49.5 & 50.8 & 50.4 & 50.2 \\
\hline Female & 50.0 & 50.5 & 49.2 & 49.6 & 49.8 \\
\hline \multicolumn{6}{|l|}{ Child's Age } \\
\hline 6 - II Months & 11.9 & 10.9 & 11.9 & 12.3 & 11.8 \\
\hline 12 - 23 Months & 20.4 & 21.5 & 22.4 & 21.6 & 21.6 \\
\hline 24 - 35 Months & 22.0 & 22.2 & 22.0 & 21.0 & 21.7 \\
\hline 36 - 47 Months & 22.6 & 22.4 & 22.5 & 22.9 & 22.6 \\
\hline 48 - 59 Months & 23.1 & 23.1 & 21.2 & 22.3 & 22.3 \\
\hline \multicolumn{6}{|c|}{ Preceding Birth Interval } \\
\hline First Birth & 14.9 & 19.9 & 21.8 & 17.6 & 18.7 \\
\hline$<18$ Months & 6.9 & 2.5 & 3.7 & 4.0 & 4.0 \\
\hline 18-35 Months & 43.1 & 26.5 & 30.2 & 36.5 & 33.8 \\
\hline 36-59 Months & 20.8 & 24.6 & 21.1 & 22.7 & 22.5 \\
\hline $60+$ Months & 5.4 & 12.9 & 13.7 & 9.2 & 10.5 \\
\hline Missing & 8.8 & 13.7 & 9.5 & 10.0 & 10.5 \\
\hline No of U5 Children & 2.4 & 1.8 & 1.9 & 2.3 & 2.1 \\
\hline Observations & 19,465 & 27,259 & 31,165 & 48,328 & 126,217 \\
\hline
\end{tabular}

\section{Analytical approach}

Frequency distributions were used to explore the nutritional status of children under-five years. Crosstabulations was used to assess the prevalence of malnutrition across the selected household and child characteristics in each region while significant differences in prevalence were assessed using chisquare tests. We fitted an ordinary logistic regression model to further examine the relationship between living arrangements and children's nutritional status while controlling for other important characteristics. Interpretation of results was done using odds ratios
(OR) with $O R>1$ implying higher risk, $O R<1$ implying lower risk and $\mathrm{OR}=\mathrm{I}$ implying no risk difference. The level of significance was set at 0.05 and a $95 \%$ confidence interval was used.

Results

Prevalence of malnutrition by socio-demographic characteristics

Results from Figure I below shows that more than half of children under-five years in Central Africa $(51 \%)$ are nutritionally healthy while the prevalence of malnutrition is lowest in the Southern African region $(37 \%)$. 
sub-Sahara Africa

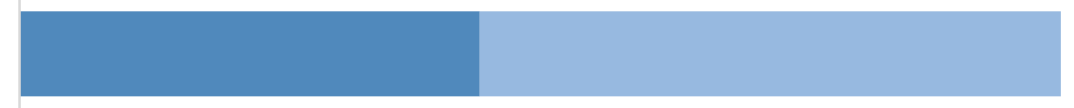

West Afria

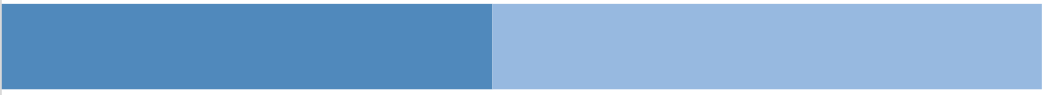

Southern Africa

East Africa

Central Africa

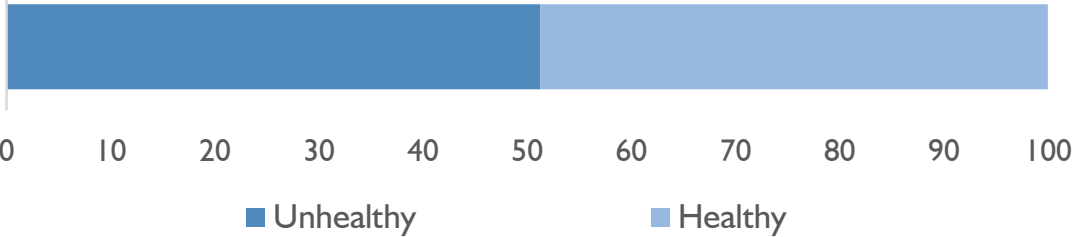

Figure I: Nutrition status of child under five years in sub-Sahara Africa and sub-regions

Table 2 below showed the prevalence of malnutrition across selected household and child characteristics. From Table 2, we found in regions (West Africa and sub-Sahara Africa) where the living arrangement was associated with malnutrition that children living with only their mother had the lowest prevalence (WA$41 \%$, SSA-42\%) of malnutrition. Children living with only their father, however, have the highest prevalence of malnutrition in both regions (WA-50\%, SSA-47\%). Across the gender or sex of household head, we found that in West (49\%) and sub-Sahara Africa (45\%), the prevalence of malnutrition was higher among children living in households headed by their father while the prevalence of malnutrition was higher among children living in households headed by their mother in Central Africa and the relationships were statistically significant. Household wealth emerged to be significantly associated with the prevalence of malnutrition in all the regions with high prevalence among children in the poorest households and a steady decline as wealth increased. The prevalence of malnutrition was higher among children in child or youth-headed households in East (47\%) and sub-Sahara Africa (45\%). Under five children in the rural place of residence also had a statistically significant high prevalence of malnutrition in SSA and across the sub-regions. In Central (56\%), East (50\%), West (54\%) and sub-Sahara Africa (51\%), we found that the prevalence of malnutrition was higher among children with less than 18 months' birth interval from their preceding births and the relationships were statistically significant. In countries where the number of under-fives within the household was associated with poor nutritional health, we found that the children with good health were residing in a household where the mean number of children under five years was lower.

Table 2: Prevalence of malnutrition by household and child characteristics

\begin{tabular}{|c|c|c|c|c|c|}
\hline & Central Africa & East Africa & Southern Africa & West Africa & Sub-Sahara Africa \\
\hline \multicolumn{6}{|l|}{ Living Arrangement } \\
\hline Living with Both Parents & 51.5 & 42.2 & 36.6 & 48.8 & 45.1 \\
\hline Living Only with Mother & 50.0 & 42.7 & 37.4 & 40.8 & 41.7 \\
\hline Living only with Father & 51.8 & 40.1 & 39.8 & 49.6 & 46.8 \\
\hline Not Living with Any & 52.2 & 40.3 & 38.5 & 44.8 & 42.7 \\
\hline$p$-value & 0.702 & 0.319 & 0.282 & 0.000 & 0.000 \\
\hline \multicolumn{6}{|l|}{ Household Head } \\
\hline Child's Father & 51.7 & 42.3 & 36.5 & 49.3 & 45.4 \\
\hline Mother & 53.4 & 41.4 & 37.7 & 39.4 & 41.5 \\
\hline Others & 47.9 & 42.2 & 37.6 & 43.1 & 42.1 \\
\hline$p$-value & 0.004 & 0.718 & 0.290 & 0.000 & 0.000 \\
\hline
\end{tabular}




\begin{tabular}{|c|c|c|c|c|c|}
\hline \multicolumn{6}{|c|}{ Household Wealth } \\
\hline Poorest & 54.8 & 50.0 & 45.7 & 59.1 & 52.9 \\
\hline Poorer & 53.6 & 44.3 & 40.4 & 54.7 & 48.8 \\
\hline Middle & 54.3 & 42.2 & 37.7 & 47.0 & 44.9 \\
\hline Richer & 53.6 & 38.4 & 31.5 & 39.7 & 39.6 \\
\hline Richest & 37.7 & 30.7 & 24.6 & 30.8 & 30.2 \\
\hline$p$-value & 0.000 & 0.000 & 0.000 & 0.000 & 0.000 \\
\hline \multicolumn{6}{|c|}{ Age of Household Head } \\
\hline Youth & 50.9 & 46.8 & 39.5 & 45.4 & 45.3 \\
\hline Working Age & 51.4 & 41.8 & 36.8 & 47.6 & 44.3 \\
\hline Aged & 49.7 & 41.7 & 37.1 & 44.4 & 42.7 \\
\hline$p$-value & 0.777 & 0.004 & 0.243 & 0.005 & 0.036 \\
\hline \multicolumn{6}{|c|}{ Place of Residence } \\
\hline Urban & 41.8 & 37.7 & 29.4 & 38.1 & 36.4 \\
\hline Rural & 54.2 & 43.8 & 40.0 & 52.3 & 47.6 \\
\hline$p$-value & 0.000 & 0.000 & 0.000 & 0.000 & 0.000 \\
\hline \multicolumn{6}{|l|}{ Child Sex } \\
\hline Male & 53.4 & 45.2 & 40.4 & 48.7 & 46.6 \\
\hline Female & 49.0 & 39.1 & 33.4 & 45.8 & 41.8 \\
\hline$p$-value & 0.000 & 0.000 & 0.000 & 0.000 & 0.000 \\
\hline \multicolumn{6}{|l|}{ Child's Age } \\
\hline 6 - II Months & 33.4 & 36.2 & 28.6 & 42.3 & 36.3 \\
\hline $12-23$ Months & 48.6 & 47.6 & 40.4 & 47.5 & 45.8 \\
\hline 24 - 35 Months & 57.3 & 48.1 & 42.0 & 51.7 & 49.4 \\
\hline $36-47$ Months & 56.3 & 41.8 & 37.7 & 49.0 & 45.8 \\
\hline 48 - 59 Months & 52.1 & 34.4 & 31.9 & 43.8 & 40.2 \\
\hline$p$-value & 0.000 & 0.000 & 0.000 & 0.000 & 0.000 \\
\hline \multicolumn{6}{|c|}{ Preceding Birth Interval } \\
\hline First Birth & 49.7 & 41.1 & 33.9 & 43.9 & 41.1 \\
\hline$<18$ Months & 56.2 & 50.0 & 39.7 & 54.5 & 51.0 \\
\hline 18-35 Months & 53.7 & 47.6 & 41.1 & 50.8 & 48.7 \\
\hline 36-59 Months & 46.9 & 40.2 & 37.2 & 47.0 & 43.1 \\
\hline $60+$ Months & 45.2 & 36.4 & 30.5 & 39.1 & 36.1 \\
\hline Missing & 51.9 & 40.4 & 38.0 & 45.6 & 43.2 \\
\hline$p$-value & 0.000 & 0.000 & 0.000 & 0.000 & 0.000 \\
\hline \multicolumn{6}{|c|}{ No of U5 Children } \\
\hline Healthy & 2.39 & 1.79 & 1.84 & 2.26 & 2.06 \\
\hline Unhealthy & 2.34 & 1.88 & 1.95 & 2.42 & 2.20 \\
\hline$p$-value & 0.055 & 0.000 & 0.000 & 0.000 & 0.000 \\
\hline Observations & 19,465 & 27,259 & 31,165 & 48,328 & 126,217 \\
\hline
\end{tabular}


African Population Studies Vol. 31, No. I, (Supp. 2), 2017

Table 3: Multivariate ordinary logistic regression model controlling for household, child and environmental characteristics

\begin{tabular}{|c|c|c|c|c|c|}
\hline & Central Africa $(19,465)$ & East Africa $(27,259)$ & Southern Africa $(31,165)$ & West Africa $(48,328)$ & Sub-Sahara Africa $(126,2 \mid 7)$ \\
\hline \multicolumn{6}{|c|}{ ADJUSTED ODDS RATIOS [CONFIDENCE INTERVALS] } \\
\hline \multicolumn{6}{|l|}{ Living Arrangement } \\
\hline Living with Both Parents & Reference & Reference & Reference & Reference & Reference \\
\hline Living Only with Mother & $0.99[0.80,1.23]$ & $1.02[0.89,1.18]$ & $\mathrm{I} .09[0.95,1.26]$ & $1.00[0.89,1.13]$ & $1.05[0.98, I .13]$ \\
\hline Living only with Father & $0.95[0.65,1.39]$ & $\mathrm{I} .04[0.72, \mathrm{I} .49]$ & I.22 [0.88, I.70] & $\mathrm{I} .20[0.98, \mathrm{I} .46]$ & $1.18 *[1.03,1.30]$ \\
\hline Not Living with Any & I.06 [0.72,I.57] & $0.94[0.74,1.19]$ & I.20 [0.90,I.59] & $1.25 *[1.02,1.54]$ & $1.13[1.00,1.28]$ \\
\hline \multicolumn{6}{|l|}{ Household Head } \\
\hline Child's Father & Reference & Reference & Reference & Reference & Reference \\
\hline Mother & $1.05[0.84,1.32]$ & $0.89[0.77,1.04]$ & $0.94[0.81,1.08]$ & $0.76 *[0.66,0.87]$ & $0.83 *[0.77,0.90]$ \\
\hline Others & $0.92[0.74,1.16]$ & $1.05[0.90,1.22]$ & $0.99[0.86,1.14]$ & $0.79 *[0.70,0.89]$ & $0.86 *[0.80,0.93]$ \\
\hline \multicolumn{6}{|l|}{ Household Wealth } \\
\hline Poorest & I.68* $[1.38,2.03]$ & $2.56 *[2.22,2.94]$ & $2.34 *[2.04,2.68]$ & $3.06 *[2.69,3.47]$ & $2.44 *[2.27,2.63]$ \\
\hline Poorer & $1.57 *[1.30,1.90]$ & $2.00 *[1.75,2.30]$ & $1.89 *[1.65,2.16]$ & $2.58 *[2.29,2.91]$ & $2.06 *[1.92,2.22]$ \\
\hline Middle & $1.66 *[1.39,1.99]$ & $1.82 *[1.59,2.09]$ & $1.71 *[1.50,1.96]$ & $1.95 *[1.74,2.19]$ & $1.81 *[1.69,1.94]$ \\
\hline Richer & $1.61 *[1.37,1.89]$ & $1.47 *[1.29,1.68]$ & $1.34 *[1.18,1.53]$ & $1.47^{*}[1.34,1.62]$ & $1.49 *[1.40,1.58]$ \\
\hline Richest & Reference & Reference & Reference & Reference & Reference \\
\hline \multicolumn{6}{|l|}{ Age of Household Head } \\
\hline Youth & $0.92[0.71,1.18]$ & $1.20 *[1.00,1.44]$ & $1.17[0.97, I .4 I]$ & $1.08[0.91,1.27]$ & $1.09[0.99,1.20]$ \\
\hline Working Age & $0.99[0.8 \mathrm{I}, \mathrm{I} .2 \mathrm{I}]$ & $1.06[0.93,1.21]$ & $\mathrm{I} .09[0.96, \mathrm{I} .24]$ & $1.09[0.99,1.20]$ & $1.07 *[1.00,1.14]$ \\
\hline Aged & Reference & Reference & Reference & Reference & Reference \\
\hline \multicolumn{6}{|l|}{ Place of Residence } \\
\hline Urban & $0.8 I *[0.69,0.95]$ & $1.23 *[1.12,1.36]$ & $0.94[0.85,1.03]$ & $0.97[0.87,1.08]$ & $0.97[0.91,1.03]$ \\
\hline Rural & Reference & Reference & Reference & Reference & Reference \\
\hline \multicolumn{6}{|l|}{ Child Sex } \\
\hline Male & Reference & Reference & Reference & Reference & Reference \\
\hline Female & $0.83 *[0.76,0.90]$ & $0.77^{*}[0.72,0.81]$ & $0.74 *[0.70,0.78]$ & $0.88 *[0.84,0.92]$ & $0.81 *[0.79,0.84]$ \\
\hline
\end{tabular}

${ }^{a}$ - the missing category includes children that are not living with their mother or both parents; ${ }^{*}-p<0.05$ 
Table 4: Multivariate ordinary logistic regression model controlling for household, child and environmental characteristics

\begin{tabular}{|c|c|c|c|c|c|}
\hline & Central Africa $(19,465)$ & East Africa $(27,259)$ & Southern Africa $(31,165)$ & West Africa $(48,328)$ & Sub-Sahara Africa $(126,217)$ \\
\hline \multicolumn{6}{|c|}{ ADJUSTED ODDS RATIOS [CONFIDENCE INTERVALS] } \\
\hline \multicolumn{6}{|l|}{ Child's Age } \\
\hline 6 - II Months & Reference & Reference & Reference & Reference & Reference \\
\hline $12-23$ Months & $1.87^{*}[1.59,2.21]$ & $1.64 *[1.48,1.83]$ & $1.70 *[1.53,1.90]$ & $1.25 *[1.16,1.35]$ & $1.50 *[1.43,1.59]$ \\
\hline 24 - 35 Months & $2.69 *[2.29,3.16]$ & $1.69 *[1.52,1.88]$ & $1.82 *[1.64,2.02]$ & $1.47 *[1.35,1.60]$ & $1.74 *[1.64,1.83]$ \\
\hline $36-47$ Months & $2.53 *[2.16,2.97]$ & $1.30 *[1.16,1.46]$ & $1.50 *[1.34,1.67]$ & $1.28 *[1.19,1.38]$ & $1.47^{*}[1.40,1.55]$ \\
\hline 48 - 59 Months & $2.13 *[1.79,2.52]$ & $0.95[0.85,1.06]$ & $1.14 *[1.02,1.27]$ & $1.04[0.95,1.13]$ & $1.17 *[1.11,1.24]$ \\
\hline \multicolumn{6}{|c|}{ Preceding Birth Interval } \\
\hline First Birth & $0.91[0.80,1.03]$ & $0.83 *[0.75,0.92]$ & $0.84 *[0.77,0.92]$ & $0.93 *[0.87,1.00]$ & $0.86 *[0.83,0.90]$ \\
\hline$<18$ Months & I.II [0.94,I.3I] & $1.13[0.93,1.37]$ & $0.98[0.85,1.15]$ & $1.21 *[1.07,1.37]$ & $1.12 *[1.04,1.21]$ \\
\hline 18-35 Months & Reference & Reference & Reference & Reference & Reference \\
\hline 36-59 Months & $0.76 *[0.68,0.86]$ & $0.80 *[0.73,0.86]$ & $0.89 *[0.82,0.97]$ & $0.90 *[0.85,0.95]$ & $0.84 *[0.81,0.87]$ \\
\hline $60+$ Months & $0.72 *[0.59,0.88]$ & $0.75 *[0.67,0.84]$ & $0.75 *[0.68,0.84]$ & $0.74 *[0.68,0.80]$ & $0.71 *[0.67,0.75]$ \\
\hline Missing $^{a}$ & $0.89[0.66,1.18]$ & $0.84[0.70,1.02]$ & $0.83[0.66,1.05]$ & $0.83 *[0.71,0.97]$ & $0.83 *[0.75,0.92]$ \\
\hline No of U5 Children & $0.95 *[0.92,0.98]$ & $1.07 *[1.03,1.11]$ & $1.01[0.98,1.04]$ & $1.04 *[1.02,1.06]$ & $1.05 *[1.04,1.07]$ \\
\hline
\end{tabular}

Relationship between children's living arrangements and nutritional status of children under-five years

Table 3 presents the results of the binary logistic regression models examining the association between children's living arrangements and nutritional status of a child under-five years while controlling for other household and child characteristics. Results showed that under-fives who were not leaving with both parents had a higher risk of poor nutrition compared to those living with both parents in West Africa [OR:I.25, Cl:I.02-I.54]. We also found that children living with only their father were significantly more likely to be malnourished compared to children living with both parents in the sub-Saharan African region [OR:I.I8, Cl:I.03-I.30]. Although we found no statistically significant associations, results also showed the risk of malnutrition is much higher for children living with only their father in East [OR:I.04, Cl:0.72-I.49], Southern [OR:I.22, Cl:0.88-I.70], and West Africa [OR:I.20, Cl:0.98, I.46] all compared to children living with both parents. In most of the regions, children living in a household headed by their mother were at a lower risk of poor nutrition although the relationship was only statistically 3646 significant in the West [OR:0.76, $\mathrm{Cl}: 0.66,0.87]$ and sub-Saharan African region [OR:0.83, Cl:0.77,0.90]. The risk of poor nutrition is almost twice for under-fives in poor household in Central [OR:I.68, Cl:I.38-2.03], East [OR:2.56, Cl:2.222.94], Southern [OR:2.34, Cl:2.04-2.68], sub-Saharan Africa [OR:2.44, Cl:2.272.63] and about three times higher risk in West Africa [OR:3.06, Cl:2.69-3.47] all compared to children residing in the richest household. In the Central Africa region [OR:0.8I, Cl:0.69-0.95], the risk of poor nutrition was higher among under-fives residing in urban areas while those in the urban areas of East Africa [OR:I.23, Cl:I.12-I.36] had a higher risk of poor nutrition compared to those residing in the rural areas. Females also had a statistically significant lower risk of malnutrition compared to males in sub-Saharan Africa [OR:0.8I, Cl:0.79-0.84] and the sub-regions. 


\section{Discussion}

Exploring the nutritional health of children under-five years in sub-Saharan Africa, this study provides empirical evidence on the association between living arrangement and nutritional status of children underfive. We hypothesised that under-five children not living with both parents will be at a higher risk of poor nutrition compared to children living with both parents. This is premised on the notion that children not living with both parents are likely to experience worse health outcomes and be less catered (Habyarimana, Zewotir, \& Ramroop, 2016; Ntoimo and Odimegwu, 20I4; Heiland and Liu, 2006).

Emerging findings from this study were consistent with the hypothesis as not living with both parents was associated with a higher risk of poor nutrition compared to living with both parents. This finding is in line with other previous studies which demonstrated that living with both parents has a protective effect against malnutrition (Olita'a, Vince, \& Tefuarani, 20l4; Mahgoub Salah, Nnyepi, \& Bandeke, 2006). Children living with both parents are likely to be in highly economic resource households which has been shown to be associated with better health outcomes among children in many Western countries and in some low-income countries especially if both parents are economically active (Van de Poel, et al, 2008; Shmueli, 2004; Lynch, et al., 2004). Coupled with higher access to quality health care services, these put under-fives in these households at a lower risk of malnutrition when compared to those living with none or one parent (Ekhator, Omuemu, \& Awunor, 20l4; Edris, 2007; Schellenberg, et al., 2003). Moreover, children from wealthier families have been shown to be more likely to receive antimalarial, and antibiotics for pneumonia (Schellenberg, et al., 2003).

Contrary to most prior studies, we found no evidence that female headed household was associated with poor nutrition (Ntoimo and Odimegwu, 20I4). Our findings suggest that children in households headed by their mother were less likely to be malnourished compared to those in households headed by their father in West and subSaharan Africa. This finding corroborates a study of children under-five years where the risk of marasmus was lower among children of single mothers compared to those of married mothers (Olamijuwon et al., 2017). This risk differences across household headship are likely to be because of the emerging rise in women empowerment economically, educationally or both which has been identified to be a contributing factor to increasing in single motherhood all over the world (Obot, 20I I). It is likely that children living in households headed by their mothers are socioeconomically better off as women who are socioeconomically dependent on their partners are more tolerant of partner abuse and at higher risk of experiencing it while women who are economically empowered may quit a violent marriage (Yount \& Carrera, 2006).

Another aspect of living arrangement that is important for under-five malnutrition in sub-Saharan Africa as shown in our study is place of residence, which has also been found to have a considerable influence on the survival of children under five years in many low-income countries where majority of the population lives in rural areas and in their majority experience extreme poverty (Macassa, 2004). This fact is related to higher access to water and sanitation, and to the concentration of better medical technology in urban areas, as well as health care service infrastructure and residents were generally more educated compared to rural residents (Macassa, 2004). More also, literature has found childhood malnutrition to occur more frequently among children from poorer households and/or poorer communities (Bain, et al., 2014; Chindime \& Ubomba-Jaswa, 2007; Fotso \& Kuate-Defo, 2006).

Our finding that males are more likely to be malnourished compared to females are supported by another study of children aged 6-12years in SouthSouth Nigeria which found a higher prevalence of stunting and underweight among males compared to females (Ekhator, Omuemu, \& Awunor, 2014). Our findings are also consistent with another study of childhood malnutrition in Kenya which found variations in the risk of stunting relative to sex with higher risk among boys when compared to girls (Olack, et al., 20I I).

There are several strengths to our findings. The first is that these data come from a well-defined geographical area using standard structured questionnaires and are representative of under-fives in sub-Saharan Africa. This has allowed us to directly compare and accurately estimate the relationship between children's living arrangement and nutritional status across the region. The second is that we have examined child malnutrition in the broader context of the household which has been neglected in most previous studies enabling a more holistic analysis of nutritional status among all children under-five years while also taking into consideration children whose mother is dead or absent.

There may, however, be limitations to these findings. First, despite training and supervision, the data on heights and weights may be subject to some nondifferential measurement error. Similarly, because the data was cross-sectional, it is quite difficult to establish causality between children's living arrangement and nutritional status. 


\section{Conclusion and recommendations}

Findings from this study document high prevalence rates of poor health among the under-five children from households headed by their father or a youth across all the sub-regions. Additionally, gender differences in the risk of undernourishment across all the regions were observed as female children were at lower risk of poor nutrition compared to males. There is a need for interventions that target nutrition programs especially to under-five children living with father only and male children. Sensitization Programs to improve nutritional access may need to account for these gendered concerns to better address child malnutrition in the region.

\section{Acknowledgement}

The authors acknowledge the support of the DSTNRF Centre of Excellence for Human Development, South Africa. Opinions expressed and conclusions arrived at are those of the authors and not to be attributed to the Centre of Excellence in Human Development and National Institute for the Humanities and Social Sciences (NIHSS)

\section{References}

Adekanmbi, V., Kayode, G \& Uthman, O. 2013. "Individual and contextual factors associated with childhood stunting in Nigeria: a multilevel analysis." Maternal \& child nutrition, 9(2), 244259.

Asfaw, M., Wondaferash, M., Taha, M \& Dube, L. 2015. "Prevalence of undernutrition and associated factors among children aged between six to fifty-nine months in Bule Hora district, South Ethiopia." BMC Public Health, I5(I), 4I.

Ayana, A., Hailemariam, T \& Melke, A. 2015. "Determinants of acute malnutrition among children aged 6-59 months in Public Hospitals, Oromia region, West Ethiopia: a case-control study." BMC Nutrition, I(I), 34.

Bain, L., Awah, P., Geraldine, N., Kindong, N., Siga, Y., Bernard, N \& Tanjeko, A. 20I4. "Malnutrition in Sub-Saharan Africa: burden, causes and prospects." Pan African Medical Journal I5(I).

Barker, D. 1997. "Prenatal influences on disease in later life. In P. Shetty, \& K. McPherson (Eds.), Diet, Nutrition and Chronic Disease: Lessons from Contrasting Worlds" (pp. 4I-58). Chichester: Wiley and Sons.

Berkman, D., Lescano, A., Gilman, R., Lopez, S \& Black, M. 2002. "Effects of stunting, diarrhoeal disease, and parasitic infection during infancy on cognition in late childhood: a follow-up study." Lancet 359, 564-57I.
Black, R., Morris, S \& Bryce, J. 2003. "Where and why are 10 million children dying every year?" Lancet 36I, 2226-2234.

Briend, A \& Collins, S. 2010. "Therapeutic nutrition for children with severe acute malnutrition: Summary of the African experience." Indian Pediatrics, 47(8), 655-659.

Chindime, C. C., \& Ubomba-Jaswa, S. (2007). Household Headship and Nutritional Status of Toddlers: An Examination of Malawian Data. African Population Studies, 2 I(2), 4573.

deOnis, M., Blossner, M., Borghi, E., Frongillo, E \& Morris, R 2004. "Estimates of global prevalence of childhood underweight in 1990 and 2015." JAMA, 29I(2I), 2600-2606.

Edris, M. 2007. "Assessment of nutritional status of preschool children of Gumbrit, North West Ethiopia." Ethiopian Journal of Health Development, 2I(2), I25-129.

Egata, G., Berhane, Y \& Worku, A. 20I4. "Predictors of acute undernutrition among children aged 6 to 36 months in east rural Ethiopia: a community based nested case-control study." BMC pediatrics, |4(I), 91.

Ekhator, C., Omuemu, O \& Awunor, N. 2014. "Assessment of the Nutritional Status of Children in a Rural Community of Central Edo State, South-South Part of Nigeria." International Journal of Community Research, I (I), I-6.

Fotso, J \& Kuate-Defo, B. 2006. "Household and community socioeconomic influences on early childhood malnutrition in Africa." Journal of biosocial science, 38(3), 289-3। 3.

Grantham-McGregor, S., Fernald, L. and Sethuraman, $\mathrm{K}$ 1999. "Effects of health and nutrition on cognitive and behavioural development in children in the first three years of life. Part 2: infections and micronutrient deficiencies: iodine, iron, and zinc." Food and nutrition Bulletin. 20, (I): 76-99.

Gurmu, E., \& Etana, D. (20I3). Household structure and children's nutritional status in Ethiopia. Genus, 69(2).

Habyarimana, F., Zewotir, T., \& Ramroop, S. (2016). Key determinants of malnutrition of children under five years of age in Rwanda: Simultaneous measurement of three anthropometric indices. African Population Studies, Vol. 30(2), 2328-2340

Heiland, F \& Liu, S. 2006. "Family structure and wellbeing of out-of-wedlock children: The significance of the biological parents' relationship." Demographic Research, I5, 6I-I04.

Kar, B., Rao, S. and Chandramouli, B 2008. "Cognitive development in children with chronic protein energy malnutrition." Behaviour and Brain Function 4, 3I. 
Karaolis, N., et al., 2007. "WHO guidelines for severe malnutrition: are they feasible in rural African hospitals?" Archives of disease in childhood, 92(3), 198-204.

Levitt, N., Lambert, E \& Norris, S. 2006. "Early life origins of adult chronic diseases: A South African perspective. In K. Steyn, J. Fourie, \& N. Temple (Eds.), Chronic Diseases of Lifestyle in South Africa: 1995-2005 (pp. 58-64). Tygerberg: Medical Research Council.

Lynch, J., Smith, G., Harper, S., Hillemeier, M., Ross, N., Kaplan, G \& Wolfson, M. 2004. "Is income inequality a determinant of population health? Part I. A systematic review." Millbank Quarterly 82, 59.

Macassa, G 2004. "Poverty and health in different contexts: Social inequalities in child mortality in Mozambique and 19th century Stockholm." Institutionen för folkhälsovetenskap/Department of Public Health Sciences.

Madhavan, S. \& Townsend, N. 2007. "The social context of children's nutritional status in rural South Africa." Scandinavian Journal of Public Health, 35(69), I07-II 7.

Mahgoub, S. Nnyepi, M \& Bandeke, T. 2006. "Extent, type of and factors affecting prevalence of malnutrition among children under three years of age in Botswana." Afr J Food Agric Nutr Dev. 6, I-5.

Mahmood, B., Hussain, S., Sohail, M., Hussain, N \& Ahmad, M. 20l4. "Assessing the level of awareness about malnutrition and poor drinking water affecting child health in district Chiniot, Punjab, Pakistan." Pakistan Journal of Nutrition I2(II), 978-982.

Motbainor, A., Worku, A \& Kumie, A. 2015. "Stunting is associated with food diversity while wasting with food insecurity among underfive children in East and West Gojjam Zones of Amhara Region, Ethiopia." PloS one, 10(8), e0I33542.

Neumann, C., Gewa, C \& Bwibo, N. 2004. "Child nutrition in developing countries." Pediatric Annals 33(I0), 658-674.

Ntoimo, L. \& Odimegwu, C. 2014. "Health effects of single motherhood on children in sub-Saharan Africa: a cross-sectional study.” BMC public health, I4(I), II45.

Obot, M. 20I4. "Socio-Cultural Persistence and Gender Under-Representation in Nigeria." Accessed from http://www.dawodu.com/obotl.htm on 15 January, 2017

Olack, B., et al. 20II. "Nutritional status of underfive children living in an informal urban settlement in Nairobi, Kenya." Journal of Health, Population and Nutrition 357-363.

Olamijuwon, E., Odimegwu, C., Gumbo, J \& Chisumpa, V. 2017. "Single motherhood and marasmus among under-five children in SubSaharan Africa: a regional analysis of prevalence and correlates." African Population Studies, $3 \mathrm{I}(\mathrm{I})$.

Olita'a, D., Vince, J \& Tefuarani, N 20I4. "Risk Factors for Malnutrition in Children at Port Moresby General Hospital, Papua New Guinea: A Case-Control Study." Journal of tropical paediatrics 60(6), 442-448.

Schellenberg, J., et al., 2003. "Inequities among the very poor: health care for children in rural southern Tanzania." The Lancet, 36I(9357), 56I566.

Shmueli, A. 2004. "Population health and income inequality: new evidence from Israeli time-series analysis." International Journal of Epidemiology, 33, 3| I-3। 7 .

UNICEF, World Health Organization, \& The World Bank. (20I2). UNICEF-WHO- World Bank. Joint Child Malnutrition Estimates: Levels \& trends in child malnutrition. Retrieved from http://www.who.int/nutgrowthdb/estimates20I I/ en/

Van de Poel, E., Hosseinpoor, A., Speybroeck, N., Van Ourti, T \& Vega, J. 2008. "Socioeconomic inequality in malnutrition in developing countries." Bulletin of the World Health Organization 86, (4): 282-29l.

Venables, P \& Raine, A. 2016. "The impact of malnutrition on intelligence at 3 and II years of age: The mediating role of temperament." Developmental Psychology, 52(2), 205.

Wachs, $T$ 1999. "The nature and nurture of child development." Food Nutr Bull 20, (I):7-22.

Wachs, T. 2008. "Multiple influences on children's nutritional deficiencies: a systems perspective." Physiology and Behaviour 94: 48-60.

Worldbank. 2008. Official list of Millenium Development Goals indicators. Retrieved March 21, 2016, from http://siteresources.worldbank.org/DATASTATIS TICS/Resources/MDGsOfficialList2008.pdf

Yount, K \& Carrera, J. 2006. Domestic violence against married women in Cambodia. Social Forces, 85(I), 355-387. 